\title{
The development of the Coalition for Oral Health for the Aging
}

\author{
Elisa M. Ghezzi, DDS, PhD* \\ Consultant, Michigan Geriatric Dentistry Network; Provider, Generations Portable Dentistry; Chair, Coalition for Oral Health for the Aging \\ (http://www.micoha.org) Adjunct Clinical Assistant Professor, University of Michigan School of Dentistry, Ann Arbor, Michigan. \\ *Corresponding author e-mail: eghezzi@umich.edu
}

Spec Care Dentist 31(5): 147-149, 2011

\section{Role of state coalitions}

The mission of the Coalition for Oral Health for the Aging (COHA; www.micoha.org) is to improve the oral health of older people through advocacy, professional education, public education, and research by focusing on prevention, health promotion, and evidence-based practices. This mission is achieved through COHA's organizational goals: (1) to be a resource for providers of care for the aging and special needs populations; (2) to promote the implementation of policies that support evidence-based strategies that provide optimal oral health for the aging; and (3) to develop collaborative partnerships that address the oral health needs of the aging and special needs populations.

As the elderly population grows, it is critical that stakeholders within states network, organize, and collaborate to address the geriatric oral health care needs in their regions. Often, this collaboration occurs through specialty professional organizations. However, since geriatric dentistry is not a recognized dental specialty, most states do not have organizations with providers who care for the oral health of the elderly. One of the functions of COHA is to fulfill the role of a statewide professional organization for oral health care providers. All members are encouraged to achieve membership in the Special Care Dentistry Association and participate at a national level as well.

Unlike a professional organization, a coalition can expand membership beyond the providers within the profession. Addressing geriatric oral health requires the collaboration of persons within the dental profession with those persons who have expertise in care of the aging and persons with disabilities. Therefore, it is critical that COHA membership include representation from a very broad base.

\section{History of $\mathrm{COHA}$}

In March 2006, COHA was established as the Michigan Geriatric Dentistry Coalition by a group of persons representing the Michigan Oral Health Coalition, the Michigan Dental Association, Delta Dental, the University of Michigan School of Dentistry, and the Michigan Department of Community Health. Currently, in addition to these groups, COHA is comprised of representatives from the Michigan Dental Hygienists' Association, the University of Detroit Mercy School of Dentistry, community public health dental providers, private practitioners, interested lay persons, and organizations that serve, for example, the aging-as well as persons with developmental disabilities (DD).

From the organization's inception, it became evident that there was not a clear understanding of the need and resources for education and clinical care of the oral health of the aging. Therefore, COHA was structured to address these information gathering and dissemination needs.

\section{Structure of $\mathrm{COHA}$}

COHA is a 501c3 nonprofit organization incorporated in the state of Michigan and governed by a member-elected executive board consisting of an executive committee (chair/treasurer/secretary/past chair), as well as workgroup chairs. COHA workgroups are organized to accomplish projects and tasks. The current workgroups include Research Workgroup, Education Workgroup, Communications and Development Workgroup, Providers and Practice Models Workgroup, and Aging Issues Workgroup. COHA meets quarterly for a 2-hour meeting, which includes a 1-hour business meeting as well as a 1-hour guest presenter and discussion. (See Table 1 for guest presenter information.)

\section{COHA Workgroups}

\section{Aging issues workgroup}

The Aging Issues Workgroup is COHA's connection to organizations outside of the dental profession. Initially, this workgroup developed a handout of all Michigan organizations that provided services to the elderly. From this start, COHA has sought expertise and recruited members from these organizations. From these relationships, $\mathrm{COHA}$ has been involved in a number of statewide organizations such as the Michigan Geriatric Education Center (http://gecm.msu.edu/), the DD Council, and the Michigan Society for Gerontology (http://www.msginfo.org/). 


\begin{tabular}{|l|l|l|}
\hline \multicolumn{2}{|l|}{ Table 1. COHA Guest presenters. } & Website \\
\hline Presenter & Organization & http://aleydiscenters.com/ \\
\hline Stuart Boekeloo & Aleydis Centers & http://www.aaa1b.com/ \\
\hline Kristin Wilson & Area Agency on Aging 1-B & http://www.deltadentalmi.com \\
\hline Nancy Hostetler & Delta Dental Foundation & http://hcam.org/ \\
\hline Pat Anderson & Health Care Association of Michigan & http://michigan.gov/miseniors \\
\hline Damita Zweiback & Healthy Aging Initiative & http://www.meadowbrookmcf.com/ \\
\hline Marna Robertson & Meadow Brook Medical Care Facility & http://www.mcrh.msu.edu/ \\
\hline John Barnas & Michigan Center for Rural Health & http://www.midental.org/ \\
\hline Greg Heintschel & Michigan Community Dental Clinics & http://gecm.msu.edu/ \\
\hline Jeff Dwyer & Michigan Geriatric Education Center & http://mohc.org/ \\
\hline Karlene Ketola & Michigan Oral Health Coalition & http://michigan.gov/miseniors \\
\hline Sarah Slocum & $\begin{array}{l}\text { Michigan State Long Term Care } \\
\text { Ombudsman }\end{array}$ & http://michigan.gov/mdch/ \\
\hline Christine Farrell & $\begin{array}{l}\text { Oral Health Program; Michigan } \\
\text { Department of Community Health }\end{array}$ & http://renaissancedental.com/ \\
\hline Thomas Dimmer & Renaissance Dental Plan & http://www.mohc.org/ \\
\hline Sybill Jeannin & Smiles Across Michigan Program & \\
\hline
\end{tabular}

Projects of this workgroup have included lecturing to, providing consultation to, and serving on boards of health services organizations; providing assistance in the development of the DD Council's Health Issues Workgroup Oral Health Position Paper; and collaborating with an Area Agency on Aging (AAA), and with students from the University of Michigan School of Dentistry, to collect oral health care supplies, which have been disseminated through the AAA's Meals on Wheels program.

\section{Communications and develop- ment workgroup}

With the establishment of a 501c3 organization, there is significant work that must be completed, including the appropriate federal and state applications and banking accounts. Identifying a pro bono attorney can be an asset in this stage of development. Focusing on grant writing, fundraising, and membership solicitation are also critical pieces of early coalition growth.

Communications development starts with a communications plan, which has established COHA's timeline for the creation of the logo, website, e-mail listserve, Facebook page, brochure, and monthly newsletters. One can join the COHA listserve by sending a request to chair@micoha.org.

\section{Education workgroup}

The focus of education in COHA is three-pronged, including (1) the education of dental professionals, (2) the education of health services providers, and (3) the education of patients and their caregivers. Identification, creation, and dissemination of educational resources for these groups in print and by electronic modality (http://omerad.msu.edu/ meded/ohe/Oral_Health_in_ElderlyCombined-Flash.html) have been a priority. COHA has an expert speaker panel that has provided more than 20 lectures to health services organizations. A lack of understanding of the extent of the challenges, as well as the training to provide oral health care to the aging, is enormous among the three target educational groups. Significant educational work remains to be done to address the current oral health care needs of the elderly, in addition to being prepared for the increased future need.

\section{Providers and practice models workgroup}

There is a tremendous need for clinical oral health care for the aging. COHA hopes to make improvements by assisting in the understanding of need, resources, and effective models of care. With the assistance of Delta Dental and the Michigan Department of Community Health, COHA surveyed all dental professionals in the state of Michigan to determine what was currently being done, as well as what providers were interested in doing to provide care to this population. From this project, Michigan Department of Community Health developed a Vulnerable Elderly Provider Directory (http://www.michigan.gov/documents/ mdch/7-10_Vulnerable_Elderly_Directory_ 7-10_329883_7.pdf) for the state. The survey results are available (http://www. micoha.org/vulnerable-elderly-survey.html) and a press release created.

In collaboration with Community Alliance, an organization that provides services to adults with special needs, COHA has sponsored Dental Days (http://communityalliance.com/oralhealth-initiatives.php), which utilizes a Michigan Public Act 161 (http://michigan. gov/documents/mdch/PA_161_Guidelines_ 293956_7.pdf) model for hygienists to provide care to underserved populations.

COHA is identifying workable models of care, which can be duplicated by dental providers to address the numerous elderly who are currently unable to obtain oral health care due to existing barriers.

\section{Research workgroup}

COHA initiated the establishment of the Michigan Geriatric Dentistry Research Collaboration, which has united academic institutions, long term care facilities, and funding organizations to support oral health research for the elderly. This endeavor has involved a clinical research project in a nursing home, oral health sections added to existing surveys, input to the State Oral Health Plan, multiple grant applications, and publications. 


\section{Future vision}

The COHA is a piece of the larger puzzle that must be put together to address the oral health care for the aging of our nation. At state levels, as well as at the national level, COHAs including stakeholders beyond the dental profession must be established to work collaboratively to prepare for the challenges in caring for an ever-growing and increasingly dentate population group. 